To put in evidence these spirochætes one may use the ultra-microscopic for fresh preparations, or one may stain with Romanowsky and similar methods. The best method is the silver nitrate one of Fontana-Tribondeau.

The $S$. bronchialis Castellani is an organism extremely variable in length, shape, and number of spirals; length 4 to 30 microns, mostly $7-14$. According to Fantham these medium forms are derived from the long ones by transverse division.

Certain individual spirochætes have very few spirals, two or three, others have a large number with spirals very close; numerous intermediate types can be found. The spirochete has been carefully investigated from a morphological standpoint by Fantham. It has not yet been cultivated. I have not been able to reproduce the disease in rabbits, guinea-pigs, and pigeons, but Chalmers and O'Farrell have reproduced the disease in a monkey by intratracheal injection.

The disease, according to certain authorities, is very contagious, the contagion taking place, according to Fantham, from infected persons to healthy individuals by means of the so-called "coccoid bodies" derived from the spirochætes. Without denying this mode of contagion, I am inclined to believe that $S$. bronohialis may be present in very small numbers in many individuals, similar to what is the case, for instance, with the pneumococcus, and that any cause lowering the vitality of the tissues, such as a chill, may cause $\boldsymbol{S}$. bronchialis to multiply and to invade the whole of the broncho-pulmonary system.

As regards the possibility of spirochætic infections spreading from the mouth to the bronchi, I must say that, except in one single case, none of my patients had any mouth lesions of spirochætic origin, and their teeth and gums were in good condition.

\section{Diagnosis and Treatment.}

Diagnosis. - This is based on finding S. bronchialis in large numbers in the expectoration, while there is absence of the tubercle bacillus, of hyphomycetes, and of ova of Paragonimus westermanii, Kerbert, which at times may give rise to bloody expectoration. Clinically, if a patient presents bloody expectoration of a vivid pink colour and is in good health, the practitioner should be on the look-out for Castellani's broncho-spirochrtosis. Cases of mixed infection of broncho-spirochrtosis and tuberculosis occasionally occur; similarly, cases of bronchial spirochætosis plus broncho. moniliasis have been recorded.

Prognosis. - The prognosis, as a rule, is favourable; in many cases all the symptoms disappear within three to four weeks from onset. Relapses, however, seem to be frequent, and chronic forms occur with expectoration, which is at times muco-purulent, greenish, and at times mixed with blood.

Treatment. - In a large number of cases active therapeutic measures are not called for, rest, nourishing diet, and country air being sufficient to bring about a cure. Frgotine and tr. iod., a few drops well diluted, should be given if the attacks of hæmoptysis are severe, and if there is not much secretion and the cough is very painful opium preparations may be administered.

As regards specific treatment arsenic and tartar emetic have been used by Castellani and others, while certain authorities recommend arsenobenzol. Satisfactory results from such a line of treatment will at times be obtained in chronic cases.

In conclusion, it seems to me that attention should be more generally paid to the presence of broncho-spirochætosis in European countries. My researches have shown, for instance, that this malady is met with in France.

In cases of patients spitting up blood a correct diagnosis is of extreme importance; it will relieve the patient's feelings to know that he is not suffering from the dreaded tuberculosis of the lnngs, but from a disease which is much less serious and generally terminates in recovery. A correct diagnosis is important also from a medico-legal point of view, because tuberculosis entails permanent discharge from the Army with a pension, while bronchial spirochætosis merely means in most cases giving the patient a few weeks' rest, after which he will be able to resume his military duties.

AT the instance of the National Council of Trained Nurses, Mrs. Bedford Fenwick will stand for election to Parliament on the National Health ticket when a suitable constituency can be found.

\section{LOCAL AN ESTHESIA AND TWILIGHT SLEEP IN THE SURGERY OF EXOPHTHALMIC GOITRE.}

By S. H. ROUQUeTTE, M.Ch. Canb., F.R.C.S. ENG., REBIDENT ABSISTANT SURGEON, ST. THOMAS'S HOSPITAL.

DURING recent years an ever-increasing number of the subjects of Graves's disease have been submitted to operation with a measure of success which would have seemed scarcely credible in days gone by before the factors of safety were as well understood as they are now. That surgery can produce an immediate cure in some cases and marked improvement in others there can be no doubt, but time alone can show whether the cure is permanent.

\section{Limitations of General Ancesthesia.}

It is generally recognised that the only surgical measure likely to prove of permanent value consists in ablation of the greater part of the gland, the exact amount depending on the age of the patient, the severity of the disease, and on various other factors. As the determination of this amount is exceedingly difficult there are many cases in which a second operation is required still further to reduce the size of the gland, but with the growth of experience secondary operations are likely to become less frequent in the future.

The very great diminution in the mortality of the operation is due partly to a better appreciation of the time at which operation should be undertaken, but far more to a realisation of the danger of anæsthetics, culminating in the absolute prohibition of chloroform. Ether is still used, and in highly skilled hands is a safe anæsthetic for very slight or early cases, as well as for those which, though originally severe, have been markedly improved by a previous operation; but I am inclined to think it is not sufficiently safe for a primary operation in a severe case.

Of the various methods of administration the rectal is achieving popularity, and has found a warm advocate in Mr. A. J. Walton and others who speak with authority. I have not made an extensive trial of this method, but such experience as I have had has only served to strengthen my preference for local anæsthesia. On several occasions Dr. $\mathrm{Z}$. Mennell has given ether for me by the intratracheal method with great success, but while I regard this as the most suitable for large, simple goitres with respiratory embarrassment, it is limited by the conditions formulated above.

\section{Local Anasthesia.}

Foremost among pioneers in this branch of surgery, Dr. T. P. Dunhill, of Melbourne, will ever be remembered as the champion of local anæesthesia; readers of THE LANCET are familiar with his teaching and aware of the results he has obtained. No one who read his paper of Dec. 15th, 1917, can fail to have been impressed by the extraordinary recovery of the most desperate cases under his care, cases which could only have terminated fatally in a very short time but for his intervention. Dr. Dunhill himself attributes his successes to the use of local anæsthesia, and, indeed, if one may judge from the photographs in his paper, it would seem doubtful whether any anæsthetist could have been found willing to deal with patients in so grave a condition.

Surgeons in this country have tried local anæsthesia, but do not seem addicted to its use. It certainly possesses two disadvantages : in the first place, the mind suffers what the body does not feel; and, in the second, the personality of the patient is apt to intrude and embarrass the surgeon, with the result that the operation may degenerate into a trying ordeal for both. In such circumstances the surgeon is hindered in his work and may be unable to remove an adequate proportion of the gland. Local anæsthesia cannot abolish the pain arising from certain of the manipulations but while some patients bravely resign themselves and tolerate discomfort without flinching, others are physically incapable of exercising the necessary self-control. When it is remembered that the patients are sufferers from Graves's disease, it will be realised that local anæsthesia must often leave much to be desired.

It was with a view to improving the technique and alleviating the distress of the patient during the operation that I began to use preliminary injections of morphine and later of hyoscine as well. I found that the operation could 
be more quickly performed and that the patient frequently felt nothing at all or slept peacefully at intervals throughout the operation. The drugs produced no ill-effects and sometimes enabled the patient to sleep for the remainder of the day.

$$
\text { Teohnique. }
$$

1. Induction of amnesia.-For each individual it is necessary to estimate what dose of the drugs will be required and how lon 5 it will take to produce the desired effect. Most frequently I give hyoscine 1/100 gr. and morphine 1/6 gr. an hour and $\mathrm{a}$ half before the operation and morphine $1 / 4 \mathrm{gr}$. half an hour later. 'The patients' ears are plugged with wool and the room is darkened at the time of the first injection.

2. Syringe and needles.-I use a $20 \mathrm{c.cm}$. Record syringe, with Barker's steel spinal needles and hypodermic needles.

3. The ancesthetic solution.-Dr. Dunhill uses $200 \mathrm{c.cm}$. of saline containing 0.1 per cent. adrenalin $20 \mathrm{~m}$ and novocaine 6 gr. Hoffmann and Kochmann ${ }^{1}$ recommend-

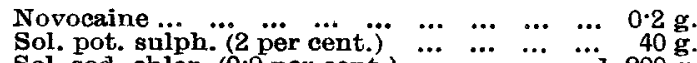

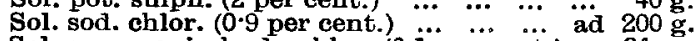

$$
\begin{aligned}
& \text { Sol. suprarenin hydrochlor. }(0 \cdot 1 \text { per cent.) ... } 24 \mathrm{~m} \text {. }
\end{aligned}
$$

The addition of potassium sulphate to a novocaine solution is said to aid its effect, and magnesium sulphate is sometimes used with a similar object. Whatever solution is employed should be freshly prepared, but need not be warmed before use. Of the two chief ingredients the adrenalin is the more important; it diminishes oozing from the subcutaneous tissues and prevents too rapid absorption of the fluid. I doubt whether the novocaine is really of any value at all at so low a concentration, as I have been equally successful with normal saline alone except for a slight increase in capillary bæmorrhage. I think the anæsthesia is produced principally by distension of the tissues, since the large volume of the fluid seems to be the most important factor.

4. The injection. - The injection can be made through one median puncture, and as the introduction of a large spinal needle is painful, it is well to begin by infiltrating the puncture area with a fine hypodermic needle. With very nervous patients I sometimes introduce a further refinement by laying a pad soaked in 1 : 20 carbolic on the neck beforehand to diminish sensibility to the prick of the needle. All the tissues superficial and lateral to the gland can be infiltrated, but the fluid does not penetrate the capsule of the gland and seldom reaches the trachea; posteriorly the structures never show any evidence of infiltration. The injection is begun half an hour before the operation while the patient is still in bed; he is then conveyed to the operation theatre, and by this time is usually drowsy and takes no interest in subsequent proceedings. It is not necessary to inject any more of the novocaine solution during the course of the operation.

5. The operation.-During the operation the theatre is kept as quiet as possible and no talking is allowed; the patient may sleep the whole time, moan subconsciously, or rouse himself at intervals to ask questions. Occasionally the limbs move slightly, but whatever impressions the brain may receive the mind retains no recollection of them. The loss of all idea of time is a noticeable feature, and when asked how long he supposed the operation took the patient will usually under-estimate the time by half an hour or more; he does not afterwards feel that he has passed through any painful ordeal, and in most cases the pulse does not rise appreciably during the operation. I have not always succeeded in producing complete immunity from discomfort, but with increased experience imperfect anæsthesia has become exceptional.

6. Post-operative course.-I always drain the wound and close the incision with clips; the drainage-tubes and some of the clips are removed two days after the operation and, if the wound then shows no tendency to gape, the remaining clips are removed on the following day. In the majority of cases the post-operative course is extraordinarily free from discomfort of any sort, the patient altogether escaping the physical and mental distress so apt to follow in the wake of general anæsthesia. The narcotics produce no ill-effects unless given in excessive doses when headache and thirst may be complained of; headaches are readily alleviated by aspirin and thirst by administration of fluids in any form most palatable to the patient.
The temperature is always raised for a few days, but usually rises no higher than $101^{\circ} \mathrm{F}$; in some cases and for no apparent reason it remains irregular for two or three weeks, and then slowly falls to normal, provided that absolute rest is enforced. The pulse reaches its highest point on the second day, and thereafter falls steadily during the next ten days to a level below that recorded before the operation. I have not found that local anæsthesia increases the likelihood of suppuration, as the wound nearly always runs an aseptic course and heals by first intention, but the formation of a hæmatoma is not unlikely to occur if more than 0.1 per cent. adrenalin $20 \mathrm{~m}$ has been used in the anæsthetic solution. Occasionally alarming symptoms arise and call for prompt treatment. Great acceleration, and particularly irregularity, of the pulse indicate fatigue, when an effort should be made to induce repose of body and of mind; in these circumstances a dose of paraldehyde in rectal saline will often bring about a marked improvement. If, in addition, the patient is dyspnœic, cyanosed, and restless the condition is more serious; the wound should first be examined to make sure that drainage is not obstructed, and then strophanthin should be injected intravenously; for this purpose 1 keep in readiness a freshly prepared solution containing strophanthin gr. 1/250 and adrenalin (0.1 per cent.) $1 \mathrm{~m}$, in $5 \mathrm{~m}$, the effect of which is instantaneous. Inhalation of oxygen is sometimes useful in relieving cyanosis.

Soreness of the throat and difficulty in swallowing are minor complaints and are sometimes distressing; they can be relieved by the use of suitable lozenges and by giving small pieces of ice to suck. Vomiting hardly ever occurs as a result of the operation and is never serious by itself, though attacks of vomiting may have been one of the manifestations of the disease. The presence or absence of various complications depends largely on the severity of the disease and on the area of the cut surface of the gland from which secretions may be absorbed into the circulation.

\section{Conclusions.}

The combination of hyoscine-morphine amnesia and local infiltration is an absolutely safe method of producing anæsthesia, possessing neither disadvantages nor contra-indications; it is preferable to local anæsthesia alone, and more rational.

\section{THE TREATMENT OF EXTENSIVE SEPTIC WOUNDS.}

BY H. GARDINER, M.S. LoND., F.R.C.S. ENG.,

AOTING ASSISTANT SURGEON, ROYAL FREE HOSPITAL AND EVELINA HOSPITAL FOR CHILDREN; OPERATING SURGEON, FULHAM MILITAR

HOSPITAI; SURGICAI REgISTRAR, CHARING CROSS HOSPITAL.

IT seems that the chief use of gauze dressing is that it protects the wound from secondary infection from outside, and that if a method of treating wounds can be devised in which the wound is protected from outside infection, and at the same time the objectionable results of the use of gauze dressings are eliminated or diminished, an advance in the right direction will have been made. With this object I have, for the last six months, been treating septic wounds with much discharge with no permanently applied dressing. The method adopted is as follows.

$$
\text { Description of the Method. }
$$

The ordinary incisions for opening up recesses in pockets are made as soon as the patient has recovered from the result of transfer to the hospital. Incisions and openings so made are performed with the idea of obtaining the maximum effect of gravity in the subsequent treatment. The wound is then packed with gauze and bandaged in the usual way- the sole object in this being to agsist in stopping oozing of blood. All dressings are removed 48 hours later. The wound is then syringed with some mild antiseptic-e.g., boric or weak eusol lotion. A guard made from perforated zinc, cat in an appropriate size and bent in the form of a cradle, is placed over the limb or part wounded and covered by a sterilised towel. If possible, an ordinary cradle is placed over the whole. Any discharge from the wound is allowed to run out from the wound, and is taken up by a sterile pad of wool or sphagnum moss so placed as not to touch the wound. At intervals varying with the amount of discharge, on an average twice a day, or in some cases more frequently, the nurse lifts the towel and zinc guard, syringes or swabs the wound, and changes the pad. The guard and towel are then replaced. This treatment is continued until all pockets and recesses have been closed by granulation, the ranulating surface is 